\title{
The effect of a lifestyle intervention on metabolic health in young women
}

This article was published in the following Dove Press journal:

Diabetes, Metabolic Syndrome and Obesity: Targets and Therapy

19 September 2014

Number of times this article has been viewed

\author{
Sarah L Dunn' \\ Winnie Siu ${ }^{2}$ \\ Judith Freund ${ }^{2,3}$ \\ Stephen H Boutcher ${ }^{2}$ \\ 'Department of Kinesiology, \\ University of La Verne, CA, USA; \\ ${ }^{2} \mathrm{School}$ of Medical Sciences, Faculty \\ of Medicine, University of New South \\ Wales, NSW, Australia; ${ }^{3}$ St Vincent's \\ Hospital, NSW, Australia
}

\begin{abstract}
With the increasing obesity rates in Western countries, an effective lifestyle intervention for fat reduction and metabolic benefits is needed. High-intensity intermittent exercise (HIIE), Mediterranean eating habits (Mediet), and fish oil ( $\omega-3)$ consumption positively impact metabolic health and adiposity, although the combined effect has yet to be determined. A 12-week lifestyle intervention on adiposity, insulin resistance, and interleukin-6 (IL-6) levels of young overweight women was administered. Thirty women with a body mass index of $26.6 \pm 0.5 \mathrm{~kg} / \mathrm{m}^{2}$, blood pressure of $114 / 66 \pm 1.9 / 1.5 \mathrm{mmHg}$, and age of $22 \pm 0.8$ years were randomly assigned to either an intervention group receiving Mediet advice, daily $\omega-3$ supplementation, and HIIE 3 days/week for 12 weeks or a control group. The group receiving Mediet advice, daily $\omega-3$ supplementation, and HIIE experienced a significant reduction in total body fat mass $(P<0.001)$, abdominal adiposity $(P<0.05)$, waist circumference $(P<0.001)$, systolic blood pressure $(P<0.05)$, fasting plasma insulin $(P<0.05)$, IL-6 $(P<0.001)$, and triglycerides $(P<0.05)$. The greatest decreases in fasting plasma insulin $(P<0.05)$ and IL-6 $(P<0.001)$ occurred by week 6 of the intervention. Significant improvements in eating habits $(P<0.05)$ and aerobic fitness $(P<0.001)$ were also found following the intervention. A multifaceted 12-week lifestyle program comprising a Mediet, $\omega-3$ supplementation, and HIIE induced significant improvements in fat loss, aerobic fitness, and insulin and IL-6 levels, positively influencing metabolic health.
\end{abstract}

Keywords: metabolic syndrome, overweight, exercise, diet

\section{Introduction}

In the US, $23 \%$ of American adults have been diagnosed with metabolic syndrome (MetS), ${ }^{1,2}$ whereas in Australia the MetS prevalence is $29 \% .^{3}$ Factors causing MetS are complex but include a physically inactive lifestyle, an unhealthy diet made up of saturated fat and processed foods, and inherited influences. ${ }^{1}$ MetS is considered a significant risk factor for heart disease ${ }^{1,3}$ and type 2 diabetes (T2DM). ${ }^{1}$ Clinical markers of MetS include obesity, dyslipidemia, hypertension, hyperinsulinemia, and elevated glucose levels. ${ }^{3}$ Inflammation induced by proinflammatory cytokines (interleukin-6 [IL-6]) and an elevated fasting insulin, also known as insulin resistance (IR), have been implicated as early MetS markers, ${ }^{4}$ and IR has been found in young adults free of other metabolic abnormalities. ${ }^{5}$

Unfortunately, regular aerobic exercise (walking and jogging) has not resulted in significant reductions in MetS criteria (fat loss), and long-duration exercise programs have poor adherence rates and are unpopular among overweight adults. ${ }^{6}$ High-intensity intermittent exercise (HIIE) is an alternative exercise protocol that is short in duration, resulting in reduced subcutaneous and abdominal adiposity ${ }^{7}$ and decreased IR. ${ }^{8-10}$
Correspondence: Sarah L Dunn Department of Kinesiology, University of La Verne, 1950 Third St, La Verne, CA 91750 , USA

Tel +I 9094484756

Fax +I 9093922760

Email sdunn@laverne.edu 
Previous research has found greater reductions in fat mass and fasting insulin following HIIE compared with steady state exercise $^{9}$ in a healthy young female population at 16 weeks in MetS patients. ${ }^{8}$ Thus, there is evidence to suggest that exposure to chronic HIIE produces improvements in body composition and IR, leading to possible reductions in inflammation, more specifically IL-6.

It has not been determined, however, whether the addition of diet modification to an HIIE program increases fat mass loss and metabolic health. For example, consuming a 2-year Mediterranean diet (Mediet) high in fibre, omega-3 ( $\omega-3)$ polyunsaturated fatty acids, and fruits and vegetables and low in red meat and saturated and trans fats has been shown to be beneficial, ${ }^{11,12}$ more specifically to decrease IR and body weight. ${ }^{13}$ In addition, after controlling for weight loss, inflammation declined and MetS prevalence was reduced by half ${ }^{13}$ following the intervention. The ingestion of $\omega-3$, abundant in the Mediet in the form of fish oils, also has beneficial effects on MetS criteria. ${ }^{14,15}$ Studies have found significant reductions in triglycerides, ${ }^{16}$ improved insulin signaling, stabilization of glucose homeostasis, ${ }^{15}$ and a reduction in fat mass when $\omega-3$ supplementation is combined with exercise. ${ }^{17}$ Several aspects of the MetS may be improved by increased intake of $\omega-3^{14}$ and adherence to the Mediet. ${ }^{18}$ However, it has been suggested that a multi-intervention approach includes the adoption of a Mediet and regular exercise involvement. ${ }^{14,17,19}$

The combined effects of HIIE, a Mediet, and $\omega-3$ ingestion on fat mass loss and metabolic health have not been examined. Consequently, the focus of this study was to investigate the effect of the combination of HIIE, a Mediet, and $\omega-3$ ingestion on fat mass loss, IR, and IL- 6 in overweight women.

\section{Subjects and methods Participants}

Volunteer premenopausal and recreationally active but untrained overweight women were recruited from a university population. Thirty-two participants were randomly allocated into one of two groups - fish oil, exercise, and a Mediet (FEM) or control (CON) - by picking a paper marked "FEM" or "CON" out of a hat. Age $(24 \pm 1.0$ years; $22 \pm 0.6$ years) and body mass index (BMI) $\left(27.6 \pm 0.8 \mathrm{~kg} / \mathrm{m}^{2}\right.$; $25.7 \pm 0.5 \mathrm{~kg} / \mathrm{m}^{2}$ ) were similar for both groups. Approval for the study was granted by the University of New South Wales Research Ethics Committee, and all participants signed the approved informed consent prior to study commencement. Previous HIIE only studies in females ${ }^{9}$ and males ${ }^{20}$ were conducted separately in our laboratory.

\section{Procedures}

Participants, who were advised to avoid strenuous activity and caffeine for 24 hours prior to testing, came into the laboratory after a 12-hour overnight fast. All tests were completed at the same time of day to avoid diurnal variation. Participants were screened for contraindications to exercise and regularity of their menstrual cycle, and personal/familial medical history was assessed.

\section{Blood pressure and cardiorespiratory fitness}

Resting blood pressure was assessed with a Colin Jentow monitor (Model 7000; Colin Medical, Japan) for pre- and post-test systolic blood pressure (SBP) and diastolic blood pressure levels in the laboratory. On a separate day, cardiorespiratory fitness was assessed using a TrueMax 2400 Metabolic Cart (ParvoMedics Inc., USA), and heart rate (HR) was recorded during this session using a Polar S810I telemetry system (Polar, Finland). After a 3-minute warm-up at 30 watts $(\mathrm{W})$ with a set pedal frequency of 60 revolutions per minute (RPM), the initial load was set at $45 \mathrm{~W}$ and was increased $15 \mathrm{~W}$ every minute until voluntary cessation and/or pedal frequency could not be maintained. All sessions were performed on an electronically braked Monark cycle ergometer, 839E (Monark, Sweden), using a two-way breathing valve and nose clip (Hans Rudolph, USA). Due to the strenuous nature of the exercise session, not all participants achieved the criteria for $\mathrm{VO}_{2 \max }{ }^{21}$ so $\mathrm{VO}_{2 \text { peak }}$ was accepted as an indicant of aerobic power.

\section{Dietary intake}

All participants were asked to complete a pre- and post-24-hour diet diary recall of food consumed on 3 separate days consisting of 2 week days and 1 weekend day. The diets were analyzed using dietary analysis software (Foodworks 2007, version 5.00; Xyris Software). Women assigned to the intervention group (FEM) ate a low glycemic Mediet and ingested three $1,100 \mathrm{mg}$ fish oil $(\omega-3)$ capsules per day for 12 weeks. Each capsule contained $550 \mathrm{mg}$ of eicosapentaenoic acid and docosahexaenoic acid per 1,100 mg capsule (YourHealth Group, Australia). The FEM women were given an overview of the healthy eating plan and recipes, along with a Mediterranean pyramid. After the initial diet sessions, FEM women were provided with feedback from their previous 1-day diet diary (every 3 weeks), and guidance was given for ways to progress toward the recommended Mediet. Use of a Mediet score (MDS) provided adherence information on a scale of 0 (least adherent) to 9 (total adherence). ${ }^{22}$ Scoring was based on the median values calculated from mean scores for all women in 
the FEM group. The CON group was asked to maintain their normal dietary habits.

\section{Body composition}

Participants completed a total body dual-energy X-ray absorptiometry (DXA) scan using a Lunar Prodigy scanner (software version 7.51; GE Corporation, USA) pre- and postintervention only, as the researchers did not have access to the equipment at the 6 -week time point. Therefore, body fat was also assessed at baseline, 6 weeks, and 12 weeks using bioimpedance (Tanita, Japan) in order to obtain a 6-week measurement. Total body, whole body fat, and fat-free mass were measured. Central (abdominal) adiposity through DXA was measured by a standard technique previously described ${ }^{23}$ and by trunk fat obtained from regional analysis of the standard Lunar software. All DXA assessments were conducted by a trained technician blinded to the randomized groups. Participants were tested in the fasted state with no liquid 2 hours prior, for standardization purposes. BMI was calculated by dividing weight by height squared $\left(\mathrm{kg} / \mathrm{m}^{2}\right)$. Waist circumference (WC) was measured according to the International Society for the Advancement of Kinanthropometry protocol ${ }^{24}$ between the lower costal border (last rib) and the iliac crest at the narrowest point.

\section{Exercise sessions}

Women who were randomly assigned to the FEM group $(n=15)$ completed 20 minutes of exercise (8-second sprint, 12-second recovery) on a manual cycle ergometer, 828E (Monark, Sweden), for each session three times a week for 12 weeks. The CON group was asked to maintain their normal exercise habits throughout the duration of the study. For the FEM women, the HIIE workload was set at $80 \%-85 \%$ of the individual's peak HR throughout each session, with a cadence between 100 RPM and 130 RPM, and recovery was set at the same amount of resistance but at a cadence of 30 RPM. The participants' average HR for a given HIIE session fell within their individual peak HR percent range, and intensity was increased when their HR fell below their peak HR percent range. All sessions were supervised, and participants performed a 5-minute warm-up and cool-down on the bike prior to and following each session. A rating of perceived exertion ${ }^{25}$ was assessed every 5 minutes, and participants cycled to a prerecorded compact disc counting down each HIIE sprint in a 3-2-1 fashion.

\section{Fasting blood specimens}

Fasting blood (total $300 \mathrm{~mL}$ ) was drawn at baseline and weeks 6 and 12 from an antecubital vein into ethylenediaminetetraacetic acid (EDTA) vacutainers. Whole blood lipid profiles including triglyceride, total cholesterol, high-density lipoprotein, low-density lipoprotein, and glucose concentrations were quantified by automated enzymatic methods (Cholestech LDX, USA). The remaining whole blood in EDTA tubes was spun immediately in a chilled centrifuge (Model Megafuge 1.0R, Heraeus, Germany) at $4^{\circ} \mathrm{C}$ and frozen at $-86^{\circ} \mathrm{C}$ for later analysis.

\section{MetS score}

Based on the clinical International Diabetes Federation (IDF) definition for MetS, ${ }^{26}$ the participants were given a point for each of the variables listed by the International Diabetes Federation and scored out of a total of 5 .

\section{Specimen analysis}

Insulin, IL-6, and adiponectin were measured using commercially available enzyme-linked immunosorbent assay kits. The degree of enzymatic turnover of the substrate was determined by dual wavelength absorbance measurement for insulin (DSL 10-1600, USA), adiponectin (R\&D DRP300, USA), and IL-6 (R\&D HS600B, USA). Although $\mathrm{C}$-reactive protein has clinical relevance regarding inflammation, IL-6 has been shown on a molecular level to increase levels of C-reactive protein in the liver and circulating blood. ${ }^{27}$ The Homeostasis Model Assessment of Insulin Resistance (HOMA-IR) was calculated as follows: HOMA$\mathrm{IR}=[$ fasting insulin $(\mu \mathrm{LU} / \mathrm{mL}) \times$ fasting blood glucose $(\mathrm{mmol} / \mathrm{L})] / 22.5$.

\section{Statistics}

Data analysis was completed with the Statistical Package for Social Science for Windows software (SPSS 18.1; USA). Student's $t$-tests were used to examine differences between the two groups at baseline and on the delta score between pre- and post-testing. Body composition measurements (percent body fat, WC) from Tanita, insulin, HOMA-IR, and IL-6 (pre, week 6, and post) were analyzed by one- and two-way repeated-measures analysis with variance, and a post hoc Bonferroni test was administered. Due to skewness, adiponectin values were log transformed for analysis. Pearson correlation analysis was used to determine associations between all variables on crude and log-transformed values. Spearman's rank order correlation was performed on values that remained skewed after $\log$ transformation. All results are expressed as mean and standard error. A $P$-value of $<0.05$ was considered significant. 


\section{Results}

Thirty-two women were recruited and 30 completed the study, with one woman unable to tolerate the $\omega$-3 and the other lost to follow-up. No significant differences were seen at baseline between the two groups. The FEM women $(\mathrm{n}=15)$ had significant increases in both absolute $\mathrm{VO}_{2 \text { peak }}(15.0 \%, P<0.001)$ and relative $\mathrm{VO}_{2 \text { peak }}(17.9 \%$, $P<0.001)$ and a significant reduction in $\mathrm{SBP}(8 \%, P<0.05)$ following the intervention compared with the $\mathrm{CON}$ group (Table 1).

In the FEM group, total body mass $(1.9 \mathrm{~kg}, 3 \%$, $P<0.001)$, fat mass $(2.6 \mathrm{~kg}, 8.3 \%, P<0.001)$, and percent body fat (measured by bioimpedance) $(F[2,22]=7.95$, $P<0.05)$ were significantly lower (Table 1 and Figure 1 ) following the intervention. Abdominal adiposity $(P<0.05)$ significantly decreased by $0.12 \mathrm{~kg}(5.0 \%)$, trunk fat by $1.2 \mathrm{~kg}$ (9.2\%), and $\mathrm{WC}$ by $3.7 \mathrm{~cm}(4.7 \%, P<0.001)$ in the FEM group compared with the CON group (Table 2).

Fasting plasma insulin significantly decreased ( $F[1.26$, $17.58]=6.72, P<0.05)$ in the FEM group by $34 \%$, and a trend in fasting HOMA-IR was found $(F[1.12,15.64]=4.33$, $P=0.05[36 \%]$ ) in the FEM group (Figure 2 and Table 3 ). The reductions in insulin and IL-6 $(F[2,28]=21.09, P<0.001)$ levels were highly correlated with baseline values $(r=-0.85$, $P<0.001$, and $r=-0.83, P<0.001$ ), and the loss in fat mass was significantly associated with the reduction in fasting insulin $(r=0.46, P<0.05)$. Glucose did not change significantly between groups (Table 3 ).

Table I Body composition and cardiorespiratory fitness before and after the 12-week lifestyle intervention

\begin{tabular}{|c|c|c|c|c|}
\hline & \multicolumn{2}{|l|}{ FEM } & \multicolumn{2}{|l|}{ CON } \\
\hline & Pre & Post & Pre & Post \\
\hline Weight (kg) & $73.3 \pm 3.1$ & $71.4 \pm 3.2 *$ & $70.9 \pm 2.9$ & $72.5 \pm 3.1$ \\
\hline BMI $\left(\mathrm{kg} / \mathrm{m}^{2}\right)$ & $27.6 \pm 0.8$ & $26.8 \pm 0.9 *$ & $25.7 \pm 0.5$ & $26.3 \pm 0.5$ \\
\hline $\mathrm{VO}_{2 \text { peak }}(\mathrm{L} / \mathrm{min})$ & $2.0 \pm 0.1$ & $2.3 \pm 0.1 *$ & $2.2 \pm 0.1$ & $2.1 \pm 0.1$ \\
\hline $\mathrm{VO}_{2 \text { peak }}(\mathrm{mL} / \mathrm{kg} / \mathrm{min})$ & $27.3 \pm 1.2$ & $32.2 \pm 1.2 *$ & $30.2 \pm 1.2$ & $28.9 \pm 1.0$ \\
\hline $\mathrm{SBP}(\mathrm{mmHg})$ & $117.3 \pm 2.9$ & $108.5 \pm 2.2 * *$ & $109.9 \pm 2.3$ & $112.1 \pm 1.9$ \\
\hline $\mathrm{DBP}(\mathrm{mmHg})$ & $67.6 \pm 2.8$ & $61.6 \pm 2.6$ & $63.8 \pm 1.6$ & $62.0 \pm 1.1$ \\
\hline $\begin{array}{l}\text { Fat mass }(\mathrm{kg}) \\
\text { by DXA }\end{array}$ & $31.5 \pm 2.4$ & $28.9 \pm 2.6^{*}$ & $26.6 \pm 1.6$ & $27.8 \pm 1.8$ \\
\hline $\begin{array}{l}\text { Percent fat mass (\%) } \\
\text { by DXA }\end{array}$ & $43.9 \pm 1.5$ & $41.2 \pm 1.8 *$ & $38.6 \pm 1.0$ & $39.5 \pm 1.2$ \\
\hline $\begin{array}{l}\text { Fat-free mass }(\mathrm{kg}) \\
\text { by DXA }\end{array}$ & $39.2 \pm 1.1$ & $39.7 \pm 1.1$ & $41.7 \pm 1.4$ & $41.9 \pm 1.5$ \\
\hline $\begin{array}{l}\text { Waist circumference } \\
(\mathrm{cm})\end{array}$ & $79.4 \pm 2.2$ & $75.7 \pm 2.1 *$ & $75.4 \pm 1.0$ & $75.4 \pm 1.3$ \\
\hline
\end{tabular}

Notes: $* P<0.001 ; * * P<0.05$. Data as mean \pm standard error.

Abbreviations: BMI, body mass index; CON, control group; DBP, diastolic blood pressure; DXA, dual-energy X-ray absorptiometry; FEM, intervention group receiving fish oil, exercise, and a Mediterranean diet; SBP, systolic blood pressure; $\mathrm{VO}_{2 \text { peak }}$, peak cardiorespiratory fitness.

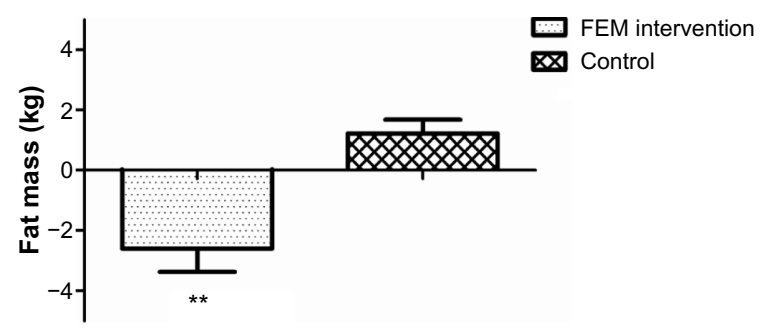

Figure I Total fat mass $(\mathrm{kg})$ loss following the I2-week lifestyle intervention for the FEM intervention and control groups.

Note: $* * P<0.001$.

Abbreviation: FEM, intervention group receiving fish oil, exercise, and a Mediterranean diet.

Insulin, HOMA-IR, and IL- 6 at week 6 had significantly $(P<0.001)$ decreased by $33 \%, 34 \%$, and $35 \%$, whereas no significant difference from week 6 to the post-test existed (Table 3 and Figure 2). Thus, the greatest decrease in insulin, HOMA-IR, and IL-6 occurred just 6 weeks into the 12-week intervention. No significant change in adiponectin (10\%) after the intervention was found.

There was a significant decrease in triglyceride $(18.1 \%$, $P<0.05$; Table 3) levels for FEM women compared with CON women, which was significantly correlated with baseline levels ( $r=-0.67, P=0.006$, Table 3$)$. All other lipid levels and the score based on the MetS IDF definition were lower following FEM but not significantly different.

Table 4 illustrates the average daily dietary patterns of the two groups. The FEM group significantly decreased their energy intake $(P<0.05)$, meat, poultry, and egg $(P<0.05)$ and cholesterol in the diet $(P<0.05)$ and significantly increased their fruit and nut consumption $(P<0.05)$. It was found that the FEM group significantly increased their MDS from $2.5 \pm 1.1$ to $4.8 \pm 1.4(P<0.001)$, representing adherence to the Mediet. No significant increase in $\omega-3$ levels or a decrease in the omega- $6(\omega-6)$ to $\omega-3$ ratio in the FEM group was noted

Table 2 Regional body composition measures before and after the I2-week lifestyle intervention

\begin{tabular}{|c|c|c|c|c|}
\hline \multirow{2}{*}{$\begin{array}{l}\text { Region of fat } \\
\text { mass }\end{array}$} & \multicolumn{2}{|l|}{ FEM } & \multicolumn{2}{|l|}{ CON } \\
\hline & Pre & Post & Pre & Post \\
\hline Leg fat (kg) & $11.6 \pm 1.0$ & $10.5 \pm 1.0 *$ & $9.8 \pm 0.8$ & $10.2 \pm 0.9$ \\
\hline Leg lean (kg) & $13.5 \pm 0.5$ & $13.8 \pm 0.5$ & $14.3 \pm 0.6$ & $14.4 \pm 0.6$ \\
\hline Arm fat (kg) & $2.8 \pm 0.2$ & $2.5 \pm 0.2^{*}$ & $2.5 \pm 0.2$ & $2.5 \pm 0.2$ \\
\hline Arm lean (kg) & $4.1 \pm 0.2$ & $4.0 \pm 0.2$ & $4.3 \pm 0.2$ & $4.3 \pm 0.2$ \\
\hline Abdominal fat (kg) & $2.0 \pm 0.2$ & $1.9 \pm 0.2^{*}$ & $1.8 \pm 0.1$ & $1.9 \pm 0.1$ \\
\hline Abdominal lean (kg) & $2.9 \pm 0.1$ & $2.9 \pm 0.1$ & $2.9 \pm 0.1$ & $3.0 \pm 0.1$ \\
\hline Trunk fat (kg) & $15.2 \pm 1.3$ & $13.8 \pm 1.3 *$ & $13.4 \pm 0.8$ & $14.2 \pm 1.0$ \\
\hline Trunk lean (kg) & $18.8 \pm 0.7$ & $19.1 \pm 0.6$ & $19.6 \pm 0.6$ & $19.8 \pm 0.9$ \\
\hline
\end{tabular}

Notes: $* P<0.05$. Data as mean \pm standard error.

Abbreviations: CON, control group; FEM, intervention group receiving fish oil, exercise, and a Mediterranean diet. 


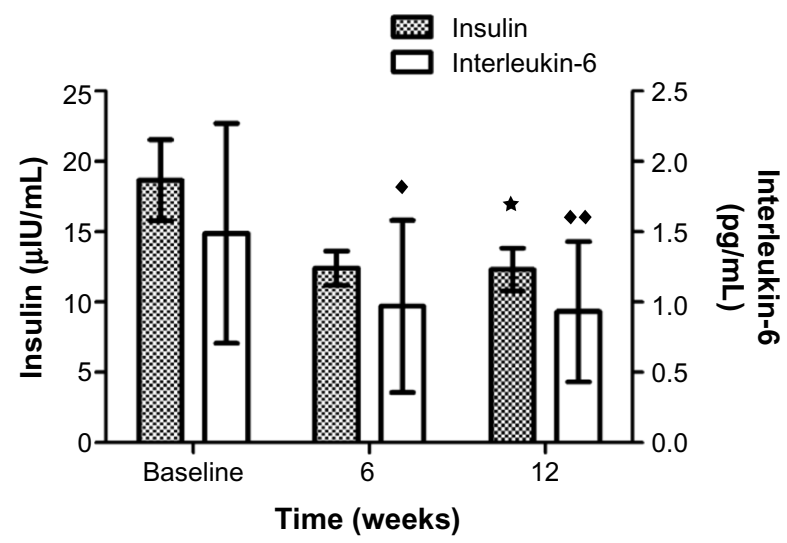

Figure 2 Insulin $(\mu \mathrm{lU} / \mathrm{mL})$ and interleukin-6 $(\mathrm{pg} / \mathrm{mL})$ levels for the FEM Intervention group at baseline, week 6 , and week 12 .

Notes: ${ }^{\otimes} P<0.001 ; \bullet P<0.05 ; \bullet P<0.001$

Abbreviation: FEM, fish oil, exercise, and a Mediterranean diet.

by examining diet alone. However, when the consumption of $\omega-3$ (capsule) was added to the analysis, the $\omega-6: \omega-3$ ratio in the FEM group was significantly lower $(P<0.001)$ at the end of the intervention compared with the $\mathrm{CON}$ group.

\section{Discussion}

After the intervention, the FEM women, compared with the CON women, significantly reduced their fat mass and

Table 3 IL-6, glucose, insulin, HOMA-IR, adiponectin, and lipids before and after the 12-week lifestyle intervention

\begin{tabular}{|c|c|c|c|c|}
\hline & \multicolumn{2}{|l|}{ FEM } & \multicolumn{2}{|l|}{ CON } \\
\hline & Pre & Post & Pre & Post \\
\hline IL-6 (pg/mL) & $1.49 \pm 0.20$ & $0.93 \pm 0.13^{*}$ & $1.35 \pm 0.34$ & $1.40 \pm 0.36$ \\
\hline $\begin{array}{l}\text { Glucose } \\
(\mathrm{mmol} / \mathrm{L})\end{array}$ & $4.68 \pm 0.13$ & $4.70 \pm 0.08$ & $4.87 \pm 0.07$ & $4.84 \pm 0.09$ \\
\hline $\begin{array}{l}\text { Insulin } \\
(\mu \mid \mathrm{I} / \mathrm{mlL})\end{array}$ & $18.68 \pm 2.88$ & $12.32 \pm 1.53 * *$ & $15.44 \pm 1.32$ & $15.88 \pm 1.82$ \\
\hline HOMA-IR & $3.99 \pm 0.76$ & $2.56 \pm 0.30$ & $3.35 \pm 0.29$ & $3.44 \pm 0.41$ \\
\hline $\begin{array}{l}\text { Adiponectin } \\
(\mu g / \mathrm{mL})\end{array}$ & $6.33 \pm 1.05$ & $6.94 \pm 1.20$ & $6.12 \pm 1.64$ & $6.85 \pm 1.81$ \\
\hline $\begin{array}{l}\text { Total } \\
\text { cholesterol } \\
(\mathrm{mmol} / \mathrm{L})\end{array}$ & $4.50 \pm 0.18$ & $4.33 \pm 0.19$ & $4.42 \pm 0.26$ & $4.57 \pm 0.32$ \\
\hline $\begin{array}{l}\text { Triglycerides } \\
\text { (mmol/L) }\end{array}$ & $0.83 \pm 0.08$ & $0.68 \pm 0.06 * *$ & $0.95 \pm 0.10$ & I. $15 \pm 0.24$ \\
\hline $\mathrm{HDL}(\mathrm{mmol} / \mathrm{L})$ & $1.42 \pm 0.10$ & $1.37 \pm 0.10$ & $1.38 \pm 0.08$ & $1.44 \pm 0.10$ \\
\hline LDL (mmol/L) & $2.70 \pm 0.15$ & $2.66 \pm 0.18$ & $2.60 \pm 0.23$ & $2.61 \pm 0.25$ \\
\hline TC:HDL ratio & $3.36 \pm 0.25$ & $3.35 \pm 0.24$ & $3.34 \pm 0.27$ & $3.25 \pm 0.20$ \\
\hline $\begin{array}{l}\text { MetS score } \\
\text { (out of } 5 \text { ) }\end{array}$ & $0.7 \pm 0.2$ & $0.4 \pm 0.2$ & $0.3 \pm 0.1$ & $0.4 \pm 0.2$ \\
\hline
\end{tabular}

Notes: $* P<0.001 ; * * P<0.05$. Data as mean \pm standard error.

Abbreviations: $\mathrm{CON}$, control group; FEM, intervention group receiving fish oil, exercise, and a Mediterranean diet; HDL, high-density lipoprotein; HOMA-IR, Homeostasis Model Assessment of Insulin Resistance; IL-6, interleukin-6; LDL, lowdensity lipoprotein; MetS score (out of 5), the participants' score for meeting the International Diabetes Federation metabolic syndrome definition, with one point given to each individual criterion; TC, total cholesterol. abdominal adiposity, WC, insulin, IL-6, SBP, and triglyceride levels. The majority of change in insulin and IL-6 had occurred by week 6 of the intervention. The FEM women conformed more to a Mediet, as confirmed by an increase in MDS and a significant reduction in saturated fat. A multifaceted lifestyle program comprising a Mediet, $\omega$-3 supplementation, and HIIE induced significant fat mass and abdominal adiposity loss after 12 weeks and produced lower insulin and IL-6 levels after 6 weeks and 12 weeks. These results support the study hypothesis by showing that this type of intervention can significantly improve MetS risk factors.

Although the women did not meet the criteria for MetS, they were overweight $\left(\mathrm{BMI}=28 \mathrm{~kg} / \mathrm{m}^{2}\right)$ at baseline, and following the intervention a reduction in fat mass of $2.6 \mathrm{~kg}(0.12 \mathrm{~kg}$ abdominal adiposity) and $\mathrm{WC}(3.7 \mathrm{~cm})$ was observed. These results support our previous laboratory findings involving 15 weeks of HIIE where a $2.5 \mathrm{~kg}$ reduction in fat mass $(0.15 \mathrm{~kg}$ in abdominal adiposity) was found. ${ }^{9}$ Therefore, a shorter intervention in individuals with greater disease risk offered similar benefits. An 8-week study involving older T2DM males found no change in body mass. However, abdominal adiposity was decreased by $44 \%,{ }^{28}$ and longer-duration HIIE (16 weeks) has provided body composition improvements in middle-aged obese women meeting the IDF definition of MetS. ${ }^{7}$ The mechanism(s) underlying the HIIE fat reduction effect is undetermined at this time. However, visceral fat exhibits higher catecholamine-induced lipolysis through increased expression of catecholamine receptors. ${ }^{29}$ Prior research in our laboratory noted that catecholamine levels increased significantly after a bout of HIIE. ${ }^{30}$ Collectively, these results indicate that HIIE protocols conducted for 12 weeks and longer result in significant decreases in fat mass and abdominal adiposity, reducing the risk of obesity and MetS.

Although the effect of HIIE on muscle mass has not been extensively examined, studies using DEXA have found that leg and trunk muscle mass were significantly increased in females by $0.6 \mathrm{~kg}$ and by $1.2 \mathrm{~kg}$ in males after 15 weeks and 12 weeks of HIIE. ${ }^{9,20}$ The $0.6 \mathrm{~kg}$ increase in leg and trunk muscle mass found after HIIE in the present study confirms the ability of this type of exercise to increase muscle mass. This effect may be important for fat loss programs, as muscle mass is typically decreased after dietary restriction ${ }^{31}$ and is typically unchanged after aerobic exercise training. ${ }^{32}$

In 2011, Esposito et $\mathrm{al}^{33}$ found improvements in body composition in overweight and obese men, some of whom met the criteria for MetS following long-term consumption (with or without caloric restriction) of a Mediet. The benefits 
Table 4 Dietary intake before and after the 12-week lifestyle intervention

\begin{tabular}{|c|c|c|c|c|}
\hline & \multicolumn{2}{|l|}{ FEM } & \multicolumn{2}{|l|}{ CON } \\
\hline & Pre & Post & Pre & Post \\
\hline Kilojoules & $7,285 \pm 468$ & $6,345 \pm 396 *$ & $6,64 I \pm 6 I 6$ & $7,485 \pm 675$ \\
\hline Carbohydrate (\%) & $44.6 \pm 1.9$ & $49.3 \pm 3.0$ & $49.3 \pm 2.1$ & $45.5 \pm 3.0$ \\
\hline Protein (\%) & $18.0 \pm 1.0$ & $19.6 \pm 1.2$ & $17.5 \pm 0.8$ & $17.3 \pm 1.2$ \\
\hline Fat $(\%)$ & $34.7 \pm 1.5$ & $30.2 \pm 2.8$ & $31.1 \pm 1.9$ & $31.7 \pm 2.0$ \\
\hline Saturated fat (\%) & $41.5 \pm 1.5$ & $38.1 \pm 2.8$ & $40.2 \pm 1.9$ & $41.4 \pm 1.1$ \\
\hline Monounsaturated fat (\%) & $41.7 \pm 1.0$ & $41.9 \pm 2.9$ & $40.8 \pm 1.7$ & $40.3 \pm 1.5$ \\
\hline Polyunsaturated fat (\%) & $16.7 \pm 1.0$ & $20.0 \pm \mathrm{I} .4$ & $19.0 \pm 1.4$ & $18.3 \pm 1.4$ \\
\hline$\omega-6$ fatty acids (diet) (g) & $8.0 \pm 0.6$ & $7.1 \pm 1.0$ & $6.8 \pm 1.1$ & $7.5 \pm 0.9$ \\
\hline$\omega-3$ fatty acids (diet) $(\mathrm{g})$ & $0.95 \pm 0.12$ & $1.04 \pm 0.21$ & $0.62 \pm 0.08$ & $0.76 \pm 0.09$ \\
\hline$\omega-6: \omega-3$ ratio (diet) & $9.4 \pm 0.8$ & $8.9 \pm 1.3$ & $11.2 \pm 1.1$ & $10.0 \pm 0.4$ \\
\hline$\omega-6: \omega-3$ ratio (diet and supplement) & $9.4 \pm 0.8$ & $2.5 \pm 0.3 * *$ & & \\
\hline Cholesterol (mg) & $264.0 \pm 33.6$ & $192.1 \pm 31.3^{*}$ & $208.8 \pm 25.8$ & $285.8 \pm 26.4$ \\
\hline Fiber $(g)$ & $19.1 \pm 1.2$ & $25.4 \pm 2.4$ & $18.8 \pm 2.5$ & $20.1 \pm 3.5$ \\
\hline Sodium (mg) & $2,839.2 \pm 287.3$ & $2,338.8 \pm 304.2$ & $2,382.3 \pm 232.1$ & $2,46 I . I \pm 248.0$ \\
\hline
\end{tabular}

Notes: $* P<0.05 ; * * P<0.001$. Data as mean \pm standard error.

Abbreviations: FEM, intervention group receiving fish oil, exercise, and a Mediterranean diet; CON, control group.

found in the current study of young sedentary but otherwise healthy women represent the combined benefits of HIIE and a Mediet. One possible mechanism may be due to the fact that the triglyceride levels were significantly lower following FEM compared with CON, which was most likely due to the Mediet because triglyceride improvements were not found in a prior interval sprinting training study. ${ }^{9}$ Total kilojoules (13\%), fat (5\%), saturated fat (3\%), and cholesterol intake (27\%) decreased in the FEM group compared with the CON group (Table 4). These results have been previously demonstrated following a 2-year Mediet (calorie reduction) and physical activity intervention in an obese population of premenopausal healthy women. ${ }^{34}$ The average two-point increase in MDS throughout the literature is considered substantial, as an increase of MDS as little as one point was found to significantly reduce mortality rates in populations by onefifth. ${ }^{35}$ More specifically, fiber (25\%) and fruit and nut (41\%) consumption significantly increased, while a significant decrease (39\%) in meat, poultry, and egg was found. These dietary improvements are believed to contribute to a significant increase $(22 \%)$ in the MDS score, representing adherence to the Mediet, which was associated with an improved fat mass and MetS variables seen previously, ${ }^{11}$ along with a reduction in diabetes risk. ${ }^{36}$ The system incorporated in the FEM investigation (MDS medians used) may have strengthened the association, as no relation to BMI in either men or women was found in a large Greek epidemiological study. ${ }^{22}$ Specific alterations within the dietary components of Mediet (less meat, poultry, and egg and greater legume intake) favorably impacted metabolic variables, lipids, and body composition following the 12-week intervention. Therefore, the combination of a Mediet (verified through an MDS) and HIIE offered additional benefits that the HIIE alone could not offer in relation to body composition and fasting whole blood triglyceride levels.

Fasting insulin decreased significantly by $32 \%$ (Table 3 and Figure 2) following the intervention and was similar to the reduction (31\%) demonstrated by Trapp et al..$^{9}$ This dramatic reduction in IR appears to be a feature of HIIE, and in healthy, nondiabetic individuals the improvement in fasting insulin and IR ranged from $23 \%$ to $33 \%$, ${ }^{9,10}$ whereas in individuals possessing T2DM two studies have reported greater insulin sensitivity improvements of $46 \%$ and $58 \%{ }^{28,37}$ The increase in insulin sensitivity may be the result of alterations in the skeletal muscle ${ }^{38}$ signaling pathways and glucose metabolism enhancing sensitivity to insulin, the lower inflammatory markers, or changes to adipocytokines and hormones. ${ }^{39,40}$ Increased insulin sensitivity has also been shown with the consumption of the Mediet. ${ }^{36}$ As previously mentioned, the increase in fiber and nut consumption along with an increase in the MDS may have contributed to the metabolic improvements currently found that were slightly better than with HIIE alone in women. ${ }^{9}$

The anti-inflammatory response (33\% reduction in IL-6, Figure 2) after 6 weeks and 12 weeks in the FEM group is similar to the results of a study performed in T2DM, obese, and lean men for 12 weeks involving 60 minutes of exercise daily with a $55 \%, 17 \%$, and $32 \%$ reduction in IL-6. ${ }^{41}$ Similarly, studies assessing the short-term consumption of the Mediet have shown reductions in low-grade systemic inflammation, ${ }^{42}$ which may be due to an increase in 
antioxidant consumption, an anti-inflammatory effect related to training, or improvements in other metabolic factors associated with low-grade systemic inflammation. ${ }^{42-44}$

Cardiorespiratory fitness levels increased significantly by $15 \%$ in the intervention group and the CON women showed no change (Table 1). Similar HIIE protocols (same laboratory, varying duration) resulted in a $15 \%-24 \%$ increase in $\mathrm{VO}_{2 \text { peak }}{ }^{9,20}$ More intense HIIE programs (12-24 weeks) have noted large increases in $\mathrm{VO}_{2 \max }{ }^{37,45,46}$ of $41 \%$ in $\mathrm{T}_{2} \mathrm{DM}^{37}$ and older cardiac rehabilitation patients. ${ }^{46}$ The effect of HIIE on cardiorespiratory fitness is impressive, given that the most intense component of HIIE is anaerobic exercise, and possible mechanisms may involve enhanced cardiac contractility, ${ }^{45}$ increased skeletal muscle buffering capacity, increased mitochondrial biogenesis, and oxidative capacity. ${ }^{47}$ Also, repeated bouts of HIIE have been shown to result in a progressive increase in adenosine triphosphate generation, so that by halfway through a bout of intense HIIE, the majority of adenosine triphosphate was generated oxidatively. ${ }^{48}$ Significant oxidative adaptations in the exercising muscle underlie the significant increases in maximal oxygen uptake documented previously after regular HIIE. ${ }^{49}$

The calculated MetS score based on the IDF definition for $\mathrm{MetS}^{3}$ decreased for the FEM women and increased for the CON women, although not significantly. Despite no significant reductions in the calculated MetS score within the FEM women, the improvements found in body composition, inflammation, and cardiorespiratory fitness are related to a lower risk for disease. ${ }^{7,11}$

A limitation of this study may involve postintervention testing and menstrual cycle. All post-testing sessions were conducted in the days immediately following, with a minimum of 24 hours between the last session and the first post-test. Due to variations in the menstrual cycle between participants, not all women were measured during the same phase of the menstrual cycle (pre and post), and some variability in water weight gain with cycle phase should be considered.

Following a 12-week multicomponent intervention, significant reductions in body composition, IR, inflammation, and triglyceride levels were found. The greatest decrease in insulin, HOMA-IR, and IL-6 had occurred by week 6 of the intervention. Therefore, an intervention trial incorporating HIIE, Mediet, and $\omega-3$ consumption improved a number of MetS criteria in young premenopausal overweight women.

\section{Acknowledgments}

We would like to thank all the participants who donated their time to the study; Dr Joachim Fleuher at YourHealth, Manly,
Australia, for the donation of the $\omega-3$ supplements; Christian Kennel for creating the LifeSprint exercise music; and Darren Irvine and Jennifer Mann for help with data collection.

\section{Disclosure}

All authors declare no conflicts of interest in any company or organization sponsoring the research currently or at the time the research was done. No funding was received for this work.

\section{References}

1. Eckel RH, Grundy SM, Zimmet PZ. The metabolic syndrome. Lancet. 2005;365(9468):1415-1428.

2. Beltran-Sanchez H, Harhay MO, Harhay MM, McElligott S. Prevalence and trends of metabolic syndrome in the adult US population, 1999-2010. J Am Coll Cardiol. 2013;62(8):697-703.

3. Alberti KG, Zimmet P, Shaw J. Metabolic syndrome - a new worldwide definition. A consensus statement from the International Diabetes Federation. Diabet Med. 2006;23(5):469-480.

4. Colca JR. Insulin sensitizers may prevent metabolic inflammation. Biochem Pharmacol. 2006;14;72(2):125-131.

5. Dvorak RV, DeNino WF, Ades PA, Poehlman ET. Phenotypic characteristics associated with insulin resistance in metabolically obese but normal-weight young women. Diabetes. 1999;48(11):2210-2214.

6. Inelmen EM, Toffanello ED, Enzi G, et al. Predictors of drop-out in overweight and obese outpatients. Int J Obes (Lond). 2005;29(1):122-128.

7. Irving BA, Davis CK, Brock DW, et al. Effect of exercise training intensity on abdominal visceral fat and body composition. Med Sci Sports Exerc. 2008;40(11):1863-1872.

8. Tjonna AE, Lee SJ, Rognmo O, et al. Aerobic interval training versus continuous moderate exercise as a treatment for the metabolic syndrome: a pilot study. Circulation. 2008;118(4):346-354.

9. Trapp EG, Chisholm DJ, Freund J, Boutcher SH. The effects of highintensity intermittent exercise training on fat loss and fasting insulin levels of young women. Int J Obes (Lond). 2008;32(4):684-691.

10. Tjonna AE, Stolen TO, Bye A, et al. Aerobic interval training reduces cardiovascular risk factors more than a multitreatment approach in overweight adolescents. Clin Sci (Lond). 2009;116(4):317-326.

11. Esposito K, Kastorini CM, Panagiotakos DB, Giugliano D. Mediterranean diet and metabolic syndrome: an updated systematic review. Rev Endocr Metab Disord. 2013;14(3):255-263.

12. Di Daniele N, Petramala L, Di Renzo L, et al. Body composition changes and cardiometabolic benefits of a balanced Italian Mediterranean diet in obese patients with metabolic syndrome. Acta Diabetol. 2013;50(3):409-416.

13. Esposito K, Marfella R, Ciotola M, et al. Effect of a Mediterraneanstyle diet on endothelial dysfunction and markers of vascular inflammation in the metabolic syndrome: a randomized trial. JAMA. 2004;292(12):1440-1446.

14. CarpentierYA, Portois L, Malaisse WJ. n-3 fatty acids and the metabolic syndrome. Am J Clin Nutr. 2006;83(Suppl 6):1499S-1504S.

15. Engler MM, Engler MB. Omega-3 fatty acids: role in cardiovascular health and disease. J Cardiovasc Nurs. 2006;21(1):17-24.

16. Harris WS. n-3 fatty acids and serum lipoproteins: human studies. Am J Clin Nutr. 1997;65(Suppl 5):1645S-1654S.

17. Hill AM, Buckley JD, Murphy KJ, Howe PR. Combining fish-oil supplements with regular aerobic exercise improves body composition and cardiovascular disease risk factors. Am J Clin Nutr. 2007;85(5): $1267-1274$.

18. Kesse-Guyot E, Ahluwalia N, Lassale C, Hercberg S, Fezeu L, Lairon D. Adherence to Mediterranean diet reduces the risk of metabolic syndrome: a 6-year prospective study. Nutr Metab Cardiovasc Dis. 2013;23(7):677-683. 
19. Landaeta-Diaz L, Fernandez JM, Da Silva-Grigoletto M, et al. Mediterranean diet, moderate-to-high intensity training, and healthrelated quality of life in adults with metabolic syndrome. Eur J Prev Cardiol. 2013;20(4):555-564.

20. Heydari M, Freund J, Boutcher SH. The effect of high-intensity intermittent exercise on body composition of overweight young males. J Obes. 2012;2012:480467.

21. Day JR, Rossiter HB, Coats EM, Skasick A, Whipp BJ. The maximally attainable VO2 during exercise in humans: the peak vs. maximum issue. J Appl Physiol. 2003;95(5):1901-1907.

22. Trichopoulou A, Naska A, Orfanos P, Trichopoulos D. Mediterranean diet in relation to body mass index and waist-to-hip ratio: the Greek European Prospective Investigation into Cancer and Nutrition Study. Am J Clin Nutr. 2005;82(5):935-940.

23. Carey DG, Jenkins AB, Campbell LV, Freund J, Chisholm DJ. Abdominal fat and insulin resistance in normal and overweight women: direct measurements reveal a strong relationship in subjects at both low and high risk of NIDDM. Diabetes. 1996;45(5):633-638.

24. Norton K, Olds T. Anthropometrica: A Textbook of Body Measurement for Sports and Health Courses. Sydney, Australia: UNSW Press; 1996.

25. Borg G. Psychological aspects of physical activities. In: Larson LA, editor. Fitness, Health and Work Capacity. New York, USA: MacMillan; 1974:141-163.

26. Alberti G, Zimmet P, Shaw J, Grundy S. The IDF Consensus Worldwide Definition of the Metabolic Syndrome. Brussels, Belgium: International Diabetes Foundation; 2006. Available from: http://www.idf.org/webdata/ docs/MetS_def_update2006.pdf. Accessed August 7, 2014.

27. Eklund $\mathrm{CM}$. Proinflammatory cytokines in CRP baseline regulation. Adv Clin Chem. 2009;48:111-136.

28. Boudou P, Sobngwi E, Mauvais-Jarvis F, Vexiau P, Gautier JF. Absence of exercise-induced variations in adiponectin levels despite decreased abdominal adiposity and improved insulin sensitivity in type 2 diabetic men. Eur J Endocrinol. 2003;149(5):421-424.

29. Ostman J, Arner P, Engfeldt P, Kager L. Regional differences in the control of lipolysis in human adipose tissue. Metabolism. 1979;28(12): 1198-1205

30. Trapp EG, Chisholm DJ, Boutcher SH. Metabolic response of trained and untrained women during high-intensity intermittent cycle exercise. Am J Physiol Regul Integr Comp Physiol. 2007;293(6):R2370-R2375.

31. Saris W. The role of exercise in the dietary-treatment of obesity. Int J Obes. 1993;17:S17-S21.

32. Stiegler P, Cunliffe A. The role of diet and exercise for the maintenance of fat-free mass and resting metabolic rate during weight loss. Sports Med. 2006;36(3):239-262.

33. Esposito K, Di Palo C, Maiorino MI, et al. Long-term effect of Mediterranean-style diet and calorie restriction on biomarkers of longevity and oxidative stress in overweight men. Cardiol Res Pract. 2011;2011:293916.

34. Esposito K, Pontillo A, Di Palo C, et al. Effect of weight loss and lifestyle changes on vascular inflammatory markers in obese women: a randomized trial. JAMA. 2003;289(14):1799-1804.
35. Osler M, Schroll M. Diet and mortality in a cohort of elderly people in a north European community. Int J Epidemiol. 1997;26(1):155-159.

36. Georgoulis M, Kontogianni MD, Yiannakouris N. Mediterranean diet and diabetes: prevention and treatment. Nutrients. 2014;6(4):1406-1423.

37. Mourier A, Gautier JF, De Kerviler E, et al. Mobilization of visceral adipose tissue related to the improvement in insulin sensitivity in response to physical training in NIDDM. Effects of branched-chain amino acid supplements. Diabetes Care. 1997;20(3):385-391.

38. Richards JC, Johnson TK, Kuzma JN, et al. Short-term sprint interval training increases insulin sensitivity in healthy adults but does not affect the thermogenic response to beta-adrenergic stimulation. J Physiol. 2010;588(15):2961-2972

39. Abete I, Parra D, Crujeiras AB, Goyenechea E, Martinez JA. Specific insulin sensitivity and leptin responses to a nutritional treatment of obesity via a combination of energy restriction and fatty fish intake. J Hum Nutr Diet. 2008;21(6):591-600.

40. Balagopal P, George D, Yarandi H, Funanage V, Bayne E. Reversal of obesity-related hypoadiponectinemia by lifestyle intervention: a controlled, randomized study in obese adolescents. J Clin Endocrinol Metab. 2005;90(11):6192-6197.

41. Dekker MJ, Lee S, Hudson R, et al. An exercise intervention without weight loss decreases circulating interleukin-6 in lean and obese men with and without type 2 diabetes mellitus. Metabolism. 2007;56(3): 332-338.

42. Estruch R. Anti-inflammatory effects of the Mediterranean diet: the experience of the PREDIMED study. Proc Nutr Soc. 2010;69(3): 333-340.

43. Richard C, Couture P, Desroches S, Lamarche B. Effect of the Mediterranean diet with and without weight loss on markers of inflammation in men with metabolic syndrome. Obesity (Silver Spring). 2013;21(1):51-57.

44. Mitjavila MT, Fandos M, Salas-Salvado J, et al. The Mediterranean diet improves the systemic lipid and DNA oxidative damage in metabolic syndrome individuals. A randomized, controlled, trial. Clin Nutr. 2013;32(2):172-178

45. Helgerud J, Hoydal K, Wang E, et al. Aerobic high-intensity intervals improve $\mathrm{VO}_{2 \max }$ more than moderate training. Med Sci Sports Exerc. 2007;39(4):665-671.

46. Wisloff U, Stoylen A, Loennechen JP, et al. Superior cardiovascular effect of aerobic interval training versus moderate continuous training in heart failure patients: a randomized study. Circulation. 2007;115(24):3086-3094.

47. Gibala MJ, McGee SL. Metabolic adaptations to short-term highintensity interval training: a little pain for a lot of gain? Exerc Sport Sci Rev. 2008;36(2):58-63.

48. Putman CT, Jones NL, Lands LC, Bragg TM, Hollidge-Horvat MG, Heigenhauser GJ. Skeletal muscle pyruvate dehydrogenase activity during maximal exercise in humans. Am J Physiol. 1995;269(3 Pt 1): E458-E468.

49. Harmer AR, Chisholm DJ, McKenna MJ, et al. Sprint training increases muscle oxidative metabolism during high-intensity exercise in patients with type 1 diabetes. Diabetes Care. 2008;31(11):2097-2102.

\section{Publish your work in this journal}

Diabetes, Metabolic Syndrome and Obesity: Targets and Therapy is an international, peer-reviewed open-access journal committed to the rapid publication of the latest laboratory and clinical findings in the fields of diabetes, metabolic syndrome and obesity research. Original research, review, case reports, hypothesis formation, expert opinion and commentaries are all considered for publication. The manuscript management system is completely online and includes a very quick and fair peer-review system, which is all easy to use. Visit http://www.dovepress.com/testimonials.php to read real quotes from published authors. 